\title{
A Critique of Epistemological Disjunctivism
}

\section{Bosuk YOON}

1. Against the persistent skepticism about the rational role of experiences in gaining knowledge about the world, John McDowell has developed in a number of writings an influential account of the nature of perceptual justification, called "epistemological disjunctivism." This paper is an attempt to provide a critical assessment of McDowell's proposal, which can be summarized in the following way.

In McDowell's view, experiences are already "saddled with" conceptual content and the content of one's experience is thus apt to figure in the judgment that results from having the experience. When one is not misled, what one takes in, that things are thus and so, is also an aspect of the world. Experience, in McDowell's well-known phrase, is "openness to the layout of reality". ${ }^{1}$ The possibility of subjectively indistinguishable deceptive experiences, he argues, does not undermine the outstanding epistemic credentials of veridical cases. If one is actually undergoing a veridical experience, one is provided with an indefeasible or factive reason for believing that things are thus and so in the world: one can just see that $\mathrm{P}$, which entails that $\mathrm{P}$ is true. Presumably, no such reason is available in a hallucinatory experience, at least for ordinary perceptual beliefs. What this means is that subjectively indistinguishable experiences can differ radically in their rational contribution. Although a veridical experience and its hallucinatory counterfeit can both be characterized as "appearances to S that P", this commonality should not be taken to support a common justifying element. According to epistemological disjunctivism, all the cases that can be characterized as "appearances to S that P" constitute an epistemically heterogeneous class: either the fact that $\mathrm{P}$ makes itself perceptually manifest to $\mathrm{S}$ or it merely seems to $\mathrm{S}$ that $\mathrm{P}$ is the case. ${ }^{2}$

Several issues arise immediately from the above summary. First, do experiences really have conceptual content? If the content of an experience is conceptual, which concepts are supposed to figure in it? Is it ordinary concepts or

Yoon, Bosuk (2015) “A Critique of Epistemological Disjunctivism”, Kilikya Felsefe Dergisi, (2) pp. 14-40.

1 John McDowell, Mind and World, p. 26.

2 I should note that the summary given does not take into account some important recent changes in McDowell's views (e.g., in “Avoiding the Myth of the Given"). I will not dwell on these changes, for they do not affect the critique put forward in this paper. 
some other concepts? It is not easy to tell what the answers are. The phenomenology of an experience does not seem helpful. As far as the phenomenology of an experience goes, its content seems far richer than what anyone can conceptualize, which is typically taken to suggest that the content of experience is at least partly nonconceptual. In this paper, I will not get embroiled in the debate whether the content of experience is conceptual, or entirely or partly nonconceptual.

The defenders of conceptual content can concede that the content of an experience is at least partly nonconceptual but still argue as McDowell does that it is only in virtue of having conceptual content that perception can play a rational role in our thinking about the world. In other words, if perception is to be placed in the "logical space of reasons", it must possess conceptual content. The defenders of nonconceptual content can reply to this by asking whether the space of reasons is really confined to the space of concepts and argue, as Richard Heck does, that the justificatory power of an experience lies in its "assertoric force" or "presentational aspect" which is shared by veridical and hallucinatory experiences but which is absent in other attitudes such as desires, intentions and mere thoughts. ${ }^{3}$ Pryor makes a similar point when he refers to the distinctive phenomenology of experiences - "the feeling of seeming to ascertain that a given proposition is true." ${ }^{\prime 4}$ I will make some remarks on the relevance of conceptual content for perceptual justification, but only toward the end of the paper.

My primary concern in this paper will be possible problems with an assumption implicit in McDowell's view about conceptual content, an assumption that can be shared by those who remain neutral to, or even oppose, his view. The assumption is that the given of an experience, understood as the totality of its rational contribution to thinking, is propositional in form. That is, if experience plays a justificatory role, the role must consist in providing propositional foundations on which the edifice of knowledge is supposed to be grounded. This idea of propositional given, abbreviated as "PG", has not gone unchallenged by some of those who attempt to preserve the rational role of experience; it has been argued that PG must be rejected to obtain a more satisfactory account of perceptual justification. ${ }^{5}$ Problems with $\mathrm{PG}$, if there are any, would afflict not

\footnotetext{
${ }^{3}$ Richard Heck, "Nonconceptual Content and the "Space of reasonss" p. 508.

${ }^{4}$ James Pryor, “What's wrong with Moore's argument?", p. 357.

${ }^{5}$ See for instance Anil Gupta, Empiricism and Experience. In writing this paper, I am much indebted to his epistemological works.
} 
only epistemological disjunctivism but also any account of the rational role of experiences that is committed to it. Yet, as I hope to show, it is especially helpful to discuss epistemological disjuncitivism in order to appreciate why PG must be reconsidered. In my diagnosis, the commitment to PG is ultimately responsible for seemingly insurmountable problems that epistemological disjunctivists run into.

I will approach the main theme by starting with a discussion of an issue that is more specific to epistemological disjunctivism: the role of subjectivity in constraining empirical rationality. Is the rational role the same for a veridical experience as for its subjectively identical hallucinatory counterpart? A consequence of accepting epistemological disjunctivism seems to be that one has to give up a highly plausible principle of perceptual justification. If my present experience, e1, gives me a reason to believe that there is a yellow cup in front of me, it seems that a deceptive but subjectively identical experience, e2, entitles me to the same belief. Although e1 and e2 may have different significances for an external observer, how is it possible that e1 puts me in a better epistemic position, with respect to rationality and justification, than e 2 does? If we are to capture the rational contribution that experiences make from the viewpoint of the experiencing subject, it seems that e1 and e2 must be equivalent in their rational contribution. ${ }^{6}$ This subjective constraint on the rational role of experiences, which I will call "SC", is apparently at odds with epistemological disjunctivism which rejects the common justifying element.

Notice that $\mathrm{SC}$ in itself does not rule out PG. SC says that subjective identical experiences have the same given, whatever the given might be. The given might be propositional. If so, SC yields that subjectively identical experiences have the same propositional given. More specifically, the propositional given may be such that an experience provides defeasible justification for an ordinary perceptual judgment.

${ }^{6}$ Pryor seems to endorse the constraint when he says that if you were in a situation that is perceptually indistinguishable from your current situation, then you would be having the same experience and thus the same ground for your belief. "The Skeptic and the Dogmatist", p.527. Michael Huemer defends a similar principle - "Internalism holds that all of the conditions that confer justification supervene on how things seem to the subject." "Phenomenal Conservatism and the Internalist Intuition", p.148. The constraint is similar to the Equivalence constraintas it is formulated by Anil Gupta -"Subjectively identical experiences make identical epistemic contributions." Gupta takes it as one of the natural constraints for an adequate account of empirical rationality. See Empiricism and Experience, p. 22. 
Or, the propositional given, as it is conceived in the traditional empiricism, may be such that an experience provides indefeasible reason for believing a proposition, say, about sense-data. It is when the given is conceived along the disjunctivist's line that SC comes to be in conflict with PG. By insisting on the possibility of factive reason, not just inconclusive reasons, for ordinary perceptual judgment and direct perceptual access to environmental facts, the epistemological disjunctivist places himself in the predicament of having to deny SC. I will discuss possible reasons that disjunctivists may have for rejecting SC and argue that none of them are convincing.

McDowell has emphasized the epistemic relevance of experiences, and, his conception of the given is intended as a way of securing the contribution of experiences for gaining knowledge about the objective world. It may be said on behalf of McDowell that SC needs not be rejected to obtain what McDowell intends to achieve with his notion of the given. If this suggestion can be worked out, there is no need to think of epistemological disjunctivism as clashing with $\mathrm{SC}$ at all. Yet, it is highly doubtful that a notion of subjectivity, robust enough to make sense of SC, is available to the disjunctivist. Thus, one can ask whether the disjunctivist conception of the given is the only way to respect the relevance of experiences for gaining access to the world. Loosening the grip that PG has on us, I will argue, can help us to see how the epistemic relevance of experiences can be saved without sacrificing SC.

2. Let us suppose, to use a familiar case, that you visit a zoo and see a zebra in a pen. According to epistemological disjunctivism, the perception can provide you with a factive reason for believing that the animal is a zebra, a reason that guarantees the truth of your belief. If it were a mule cleverly painted to look like a zebra, you would have a subjectively identical experience and thus, by SC, you must also have the factive reason for the same belief. Yet, the ground you would have, if it were a painted mule, for believing that the animal is a zebra can't be factive simply because the animal isn't a zebra. Thus, either the perception can't give a factive reason or SC must be rejected. In this way, epistemological disjunctivist comes to reject the subjective constraint. 
What are the reasons that can be provided for the claim that subjectively identical experiences can differ in their rational contribution?

An answer may come from an externalist account of empirical rationality. Since subjectively identical experiences can differ with regard to how they are contingently related to environmental facts, this external difference, it may be argued, is relevant for explaining their different rational contribution. McDowell's answer to how veridical experience and its hallucinatory counterfeit differ in their given, however, does not seem to fit the externalist framework, on which many commentators seem to agree. It has been suggested instead that McDowell's approach should be understood as revolting against some common assumptions shared by traditional internalism and externalism.

A clue to McDowell's own answer can be found when he says that the disjunctivist's alternative "is liable to be obscured from us by a certain tempting line of argument", and he describes the tempting line of argument as "an application of the Argument from Illusion". ${ }^{8}$ The Argument from Illusion starts with a particular case of illusion, for instance, a stick immersed in water, then moves to the existence of an object other than the stick and finally reaches the general conclusion that all perceptions are of special inner objects. There have been many criticisms of the

\footnotetext{
${ }^{7}$ Some disjunctivists may argue that they do not reject SC formulated in terms of subjective identity. How is it possible that veridical perception puts us in a better epistemic position than a hallucination? Ram Neta claims that McDowell's answer is that the only satisfactory explanation of the fact is that veridical perception and hallucination are subjectively different. Let us suppose that Neta is correct about McDowell's answer. But why should we think that veridical perception and hallucination are subjectively different? Neta's answer is this: veridical perception and hallucination are subjectively different in the sense that "a person who is enjoying veridical perception has reflectively accessible reasons for belief that are not possessed by the person who is merely having a hallucination." Subjective difference is rendered as a matter of difference in reflectively accessible reasons. If the subjective identity of two experiences is defined in terms of the identity of epistemic reasons afforded by them, it is no wonder that subjectively identical experiences have the same epistemic significance. But this is not how SC is intended by its defenders: they take it as providing a substantial constraint on the rational contribution of experiences. Thus, as long as SC is understood in the way it is intended by its defenders, a disjunctivist can't avoid the conflict with SC by saying that different epistemic significance of a veridical experience and its hallucinatory counterpart is not a counterexample to SC because they are not subjectively identical. See Ram Neta, "In Defence of Disjunctivism".

8 John McDowell, “Criteria, Defeasibility and Knowledge”, pp. 385-386.
} 
Argument from Illusion, but what is especially central to McDowell's criticism is the validity of the final, generalization step. Even if all we can directly perceive in the case of illusions and hallucinations are special subjective entities such as sense-data, why should this, McDowell asks, be generalized to the cases of veridical experiences? Those who follow McDowell in taking experiences not as 'an interface between subject and world' but as 'openness to the world' may object to $\mathrm{SC}$ by saying that $\mathrm{SC}$ is rooted in the faulty picture of the mind in which the self is kept within the circle of its own sensations, sense-data, or impressions.

While the Argument from Illusion is problematic in many ways, we need to distinguish the discussion about the objects of direct perception from the current discussion about the rational role of perception. SC does not presuppose that in having sensory experiences, we are presented something that mediates perception of objects in the environment. We need not create an interface between us and the world in order to acknowledge, following SC, that the subjective character of an experience determines its rational contribution. SC is compatible with the possibility that the subjective character of experience is determined by properties of the external objects seen or heard, the possibility taken seriously by the "relational view of experience". SC itself does not rule out such an account of experience. The following remark is from Tim Crane's paper where he articulates the relational view.

From the subject's point of view, experience seems to be a kind of 'openness to the world': how things are in the perceptual experience is partly determined by how things are with the objects of experience. And how things are in an experience is partly determined by how the objects of experience are at the time at which one is experiencing them. ${ }^{9}$

If 'openness to the world' is understood in this way, SC is fully compatible with it. The defenders of SC can grant that it might be external objects, say, a yellow cup that is directly presented to consciousness. Even if the subjective character of my seeing a yellow cup is actually determined by the cup and its properties, the converse determination does not hold: the subjective character does not necessarily determine the cup and its properties. Even if my experience of seeming to see a yellow cup actually results from seeing a yellow cup under normal lighting conditions, it or a subjectively identical experience might come from seeing a white cup under a yellow light or in normal light but while wearing yellow sunglasses, or even from merely hallucinating a yellow cup.

\footnotetext{
${ }^{9}$ Tim Crane, “Is There a Perceptual Relation?”, p. 134.
} 
Since SC is not based on anything like the faulty picture of mind that immediate objects of perception are restricted to sense-data, it shouldn't be blamed for the problems that arise for such a picture. For example, the picture has been criticized for undermining the very idea of an experience having as its content that things are thus and so in the external world. Suppose that the objects of experience are not the familiar objects in the environment, but mere appearances or sense-data which in general intervene between the experiencing subject and the world. A question immediately arises as to how experiences can even purport to be of the external environment. This question may well have no easy answer. But this has no bearing on the status of SC, for SC is compatible with the possibility that external objects are directly presented to us in experiences.

I have claimed that one can accept SC without presupposing a particular account of the nature and object of experience. An objection to this claim may be distilled from Byrne and Logue's interpretation of disjunctivism. They note first that epistemological disjunctivism is consistent with the rejection of metaphysical disjunctivism, the idea that veridical perception and its hallucinatory counterfeit are fundamentally different kinds of mental state and at best disjunctively like the class of "ravens-or-writing-desks". ${ }^{10}$ They take this to be important for understanding the kind of disjunctivism favored by McDowell. Byrne and Logue claim further that metaphysical disjunctivism does not entail epistemological disjunctivism either, but, they go on to argue that the former "leads naturally if not inexorably to" the latter. ${ }^{11}$ This means that those who accept SC and reject epistemological disjunctivism are more likely to be committed to the rejection of metaphysical disjunctivism. This would be a bad news for the proponents of SC who say that although subjectively identical experiences can't differ in their rational contributions, they may be quite different in their objective nature, as the metaphysical disjunctivists claim they are. If Byrne and Logue are right, SC can't be easily taken to be neutral to the ultimate nature of the subjective character of experience and this goes against SC as I interpret it.

Why is it not easy to combine metaphysical disjunctivism with a rejection of epistemological disjunctivism? Byrne and Logue's explanation goes like this. Suppose that we follow some metaphysical disjunctivists and grant that while

\footnotetext{
${ }^{10}$ Alex Byrne and Heather Logue, "Either/Or", p. 59.

${ }^{11}$ Alex Byrne and Heather Logue, ibid., p. 67.
} 
it is the external object itself, says, a tomato, that one is acquainted with in a veridical experience, one is acquainted at best with something like a sense-datum in a corresponding hallucinatory experience. What, Byrne and Logue ask, are perceptual evidences in each case for the proposition that there is a red spherical thing before one? Perceptual evidence that can be provided by a hallucinatory experience is "nothing stronger than facts about sense-data." Yet, this can't be true of a veridical experience of seeing a tomato because, according to the above version of metaphysical disjunctivism, no sense-data are involved in a veridical episode. Presumably, an experience can't provide an evidence for something that is not even presented in it. Thus, perceptual evidence in the veridical case may be a fact about a particular tomato or some general fact about the external world. Thus, the common perceptual evidence can only be the disjunction of what are available in the good case and the bad case - something like "there is a tomato or there is a tomato-sense-datum." Such common perceptual evidence is not sufficient for securing the knowledge that there is a tomato. Yet, to refute epistemological disjunctivism, the critic must show that the common evidence suffices for knowledge.

This argument trades, however, on a certain ambiguity in the kind of relation that figures in characterizing metaphysical disjunctivism. If metaphysical disjunctivism is taken to be committed to an epistemic reading of "being acquainted with objects", then metaphysical disjunctivism, contra Byrne and Logue's interpretation, would entail epistemological disjunctivism. If metaphysical disjunctivism is not so committed, their argument needs a specific assumption about how the rational contribution of an experience is to be characterized, for instance, the assumption that an experience reveals facts about the objects that are presented in the experience. Only in conjunction with this assumption does metaphysical disjunctivism lead to the conclusion that the rational contribution of a veridical experience and its hallucinatory counterfeit are different: they both provide factive reasons for beliefs about quite different states of affairs. Without the assumption, it is not clear at all why metaphysical disjunctivism should have any tendency to lead to epistemological disjunctivism. Although two experiences may differ objectively in virtue of the fact that they are related to very different sort of objects, as the metaphysical disjunctivist claims, it is consistent with this to say that they should make the same rational contribution as long as they are subjectively identical. 
Byrne and Logue's argument that metaphysical disjunctivism leads naturally to epistemological disjunctivism and the rejection of SC is based on the controversial assumption that direct presentation of an object reveals to us facts about it. ${ }^{12}$ Until the assumption is adequately defended, those who accept $\mathrm{SC}$ and reject epistemological disjunctivism need not be disturbed by the charge that they are committed to a picture of mind that leaves no room for metaphysical disjunctivism.

3. McDowell has often criticized something similar to SC, namely, "the highest common factor conception", according to which the warrant for a perceptual claim can never be better than what can be provided by the bad cases "Neither of the admittedly indistinguishable experiences could have higher epistemic worth than that of the inferior one."13 On McDowell's diagnosis, the highest common factor conception is responsible for the Cartesian view, the idea of subjective foundation, and thereby skepticism about knowledge of the external world. Once the Cartesian starting point is accepted, the skepticism is difficult to resist. Given that experiences inform us at best about the subjective realm, how is the inference to the mind-independent world justified? McDowell thinks that we should not take this question seriously. On McDowell's diagnosis, the skeptical challenge is made more urgent than it should be due to the implicit adherence to the skeptic's conception of the rational role of experience which is shaped by the highest common factor conception. Those who have tried to resist the skeptical conclusion by inheriting the impoverished conception of the rational role have been fighting a war in the enemy's territory. McDowell's way out is simply to remove a prop on which the skeptical doubt depends. He replaces the highest common factor conception with the disjunctivist's alternative, according to which the rational role of a veridical experience is considerably better than what is afforded by the subjectively indistinguishable hallucinatory counterfeit. ${ }^{14}$ It may be suggested that McDowell's argument against the highest common factor conception, viz., that it leads to the Cartesian view can be extended to SC.

${ }^{12}$ Crispin Wright says, "Direct awareness of states of affairs that make P true is one thing; warranted belief that $\mathrm{P}$, for one fully apprised of what it takes for $\mathrm{P}$ to be true, is something else." See his "Comment on John McDowell's 'The Disjunctive Conception of Experience as Material for a Transcendental Argument." P. 398.

${ }^{13}$ John McDowell, "The Disjunctive Conception of Experience as Material for a Transcendental Argument”, p. 381.

${ }^{14}$ John McDowell, ibid., p. 384. 
First of all, notice that $\mathrm{SC}$, in contrast to the highest common factor conception, is stated in terms of subjective identity, not subjective indistinguishability. The latter concerns the subject's ability to distinguish experiences; the former concerns how it is with the subject as she undergoes experiences. Two experiences separated in time may fail to be subjectively identical and yet, because of memory limitations, the subject may be unable to distinguish between them. The subject may judge them to be exactly the same. The other possibility can also obtain: a subject may erroneously judge subjectively identical experience to be different. Unless subjective identity is confused with the subject's ability to distinguish experiences, there is no reason to think that if one endorses $\mathrm{SC}$, one must also endorse the highest common factor conception. Those who endorse SC can allow that subjectively indistinguishable experiences, as long as they are not subjectively identical, may differ in their given. Thus, McDowell's arguments against the highest common factor conception, even if they are sound, do not affect SC.

Furthermore, the highest common factor conception - "neither of the admittedly indistinguishable experiences could have higher epistemic worth than that of the inferior one" - leads to the Cartesian view because the epistemic worth of the inferior experience or the bad case is taken to be propositions about the subjective realm. Only in conjunction with this particular assumption about the epistemic worth of the inferior experience does the highest common factor conception entail the Cartesian view. Without the assumption, it is not clear at all that the highest common factor conception forces the view that epistemological significance of experiences is restricted to the subjective realm. This is also true of $\mathrm{SC}$. As far as SC is concerned, all it says is that subjectively identical experiences make the same rational contribution. As an abstract constraint, SC is compatible with different characterizations of the given. For instance, SC can be accepted by those who believe that experiences provide immediate justification for ordinary external propositions. If one's experience of seeing a red apple justifies the belief that there is a red apple in front of one, an experience subjectively identical to it can also justify the same belief. SC in itself has no tendency to force the Cartesian view. The subjectivist orientation embodied in SC is distinct from the idea of subjective foundations.

The Cartesian view, the view that restricts the epistemic significance of experiences to the subjective realm, has been much criticized for making knowledge of the external world problematic and mysterious. Various attempts have been made to bridge the gap between, on the one hand, what experiences can 
afford to us on such a view and, on the other, ordinary judgments of perception, but without much success. This has been taken to motivate skepticism about the rational role of experience in guiding us to knowledge about the world and, indeed, the rejection of empiricism itself. McDowell himself characterizes his project as an attempt to rebuild empiricism by deconstructing the underlying Cartesian view.

The present issue, however, is whether we must reject $\mathrm{SC}$ in order to avoid the Cartesian view. McDowell thinks that SC or something like it is the real culprit that is responsible for the Cartesian view and the problematics of the traditional empiricism. But SC only with a certain particular conception of the given has any chance of leading to the Cartesian view. As I argued in the previous section, the claim that external objects or facts are directed presented in an experience may lead to the falsity of SC only when direct presentation is given a special epistemological significance. This assumption is precisely what underlies the Cartesian view. Even if we are presented only with sense-data in perception, this in itself does not entail the Cartesian view. Only when presentation with sensedata is given an epistemic significance, the highest common factor conception or $\mathrm{SC}$ has any chance of motivating the Cartesian view. If the disjunctivist is to argue against $\mathrm{SC}$ by saying that it leads to the Cartesian view, the argument should not presuppose the notion of the given that is no less questionable than $\mathrm{SC}$ itself.

If the above discussion is on the right track, it isn't the case that epistemological disjunctivism is the obvious way to oppose the Cartesian view and those who accepts SC and deny epistemological disjunctivism are in the predicament of having to find a way to distance themselves from the Cartesian view.

4. I have argued that there is no good reason, independently of the assumptions central to epistemological disjunctivism, for rejecting SC. McDowell can respond to the above discussion by first granting that $\mathrm{SC}$ can be detached from the Cartesian view and then arguing that SC eventually leads to skepticism about knowledge of the external world. That is, as long as one is faithful to SC, one runs into the skeptical problem in one way or another. Now, it is true that although SC allows immediate perceptual justification of an external proposition, the justification can be at best defeasible. If it were a painted mule, you would be justified to believe that the animal is a zebra. Yet, this justification can't be such as to guarantee the truth of your belief. It is possible then that our perceptual beliefs are justified just as well as any within the restriction set by SC but still we are systematically cut loose from how things are in the world. In contrast, the disjunctivist's account of 
perceptual knowledge contains the requirement of factive reason. For instance, Prichard's book on epistemological disjunctivism is dedicated to a defense of the following thesis about perceptual knowledge:

In paradigmatic cases of perceptual knowledge, an agent, S, has perceptual knowledge that $\varnothing$ in virtue of being in possession of rational support, R, for her belief that $\varnothing$ which is both factive (i.e., R's obtaining entails $\varnothing$ ) and reflectively accessible to $\mathrm{S}{ }^{15}$

Whether this particular account is plausible or not, it is clear that the dominant concern for the disjunctivist is the possibility of perceptual knowledge, not just perceptual justification. Indeed, McDowell has emphasized the need for receptive knowledge, knowledge immediately yielded by experience, in order to render empirical rationality intelligible. His view of the given of an experience is shaped by the thought that the given consists in its contribution to the subject's opportunities for knowledge - "Givenness should be givenness for knowing". ${ }^{16}$ Underlying McDowell's conception of the given, I think, is the idea that the given itself is not responsible for an error or falsity that may result from undergoing the experience. If the rational input from experiences to our thinking can mislead us, what other resources do we have for correcting the mistakes? If we have to rely on other experiences, how can these experiences, capable of providing at best defeasible justification, adjudicate our claims based on earlier experiences? I take this to be the correct intuition behind McDowell's conception of the given.

Whether defeasible justification never suffices for knowledge, however, is debatable. Does knowledge requires indefeasible reason that guarantees the truth of belief? It has been claimed that we can have knowledge on the basis of defeasible justification, justification that does not guarantee that our beliefs are true. That is, justification one gets from merely having an experience as of $\mathrm{P}$ can sometimes suffice for knowledge that P. ${ }^{17}$

When is the defeasible perceptual justification sufficient for knowledge though? Presumably, defeasible justification one gets from illusory or hallucinatory experiences does not suffice for knowledge. Veridical experiences are no better at least in the following cases. Consider, for instance, a perceptual Gettier-case

\footnotetext{
${ }^{15}$ Duncan Prichard, Epistemological Disjunctivism, p. 13.

${ }^{16}$ John McDowell, "The Given in Experience: Comment on Gupta”, p. 470.

${ }^{17}$ James Pryor, "The skeptic and the dogmatist", p. 520.
} 
in which a traveler sees a dog in the field that looks like a sheep and believes that there is a sheep in the field and it also happens that there is a sheep in the field hidden from view. The traveler seems to have a justified true belief but does not know that there is a sheep in the field. The same point can be made with the following example due to Grice. Suppose that it seems to one that there is a white pillar in front of one and that there is in fact such a pillar. But the pillar is occluded behind a mirror and one is actually seeing a numerically distinct white pillar reflected on the mirror. If one goes on with one's experience in such a case, one's belief that there is a white pillar in front of one would be true and thus one is not misled by one's experience, but one can hardly be said to know that there is a white pillar in front of one.

Now, if justification one gets from merely having an experience as of $\mathrm{P}$ can, barring the perceptual Gettier-cases, suffice for knowledge that $\mathrm{P}$, what explains the different epistemic significance of two equally justified beliefs? It seems that McDowell's account, equipped with the notion of direct awareness, can provide an explanation: there is no direct awareness of the fact that there is a sheep and that is why the traveler does not know the fact. Given that direct awareness can serve a rational role, the traveler does not know because he does not have the kind of justification needed for knowledge.

Although the disjunctivist seems to have a resource to explain the lack of knowledge in the Gettier cases, it remains to be seen whether providing such an explanation needs to be a part of an account of empirical rationality. When empirical rationality falls short of delivering knowledge, this may be due to factors foreign to empirical rationality. Even if direct awareness does explain the presence of knowledge, direct awareness may be one such factor that has nothing to do with empirical rationality. This is at odds with McDowell's demand for receptive knowledge in order to render empirical rationality intelligible.

Furthermore, those who are skeptical of the justificatory relevance of direct awareness can raise the following question. If givenness is givenness for knowing, how can we make sense of the rationality of ordinary perceptual judgments made on the basis of hallucinatory or illusory experiences? It is difficult to understand on McDowell's account how the subject of hallucination can be justified to believe in an external proposition. Let us suppose that in veridical perception, the subject knows whereas in hallucination, the subject fails to know. Since no knowledge or factive reason is provided in the hallucinatory case, this entails for 
McDowell's account that there is no given in a hallucinatory experience. If the given of an experience is supposed to capture the total rational contribution of the experience and givenness is givenness for knowing, how can a mere seeming which presumably is incapable of presenting opportunities for knowing be said to make a rational contribution? It seems that McDowell has to bite the bullet and deny the rationality of judgments based on hallucinatory experiences.

McDowell suggests in the following passage, however, that there is no problem for him to accept the rationality of judgments based on hallucinatory experiences.

It is true that if someone has an experience in which she seems to perceive that things are thus and so, that can make her believing that things are thus and so rationally intelligible, even if the seeming is mere seeming. Taking a mere appearance for reality may be rationality at work. ${ }^{18}$

If McDowell does not wish to deny the rationality of perceptual judgments based on illusory or hallucinatory experiences, the only option available to him seems to be to deny that the given of an experience captures its rational contribution. If hallucinatory experience does not yield knowledge and givenness is givenness for knowing, hallucinatory experience does not have a given. Yet, if taking a mere appearance for reality may be rationality at work, the given of an experience can't be what captures its rational role. McDowell's notion of the given turns out to be irrelevant for empirical rationality.

Duncan Prichard, in interpreting McDowell's view, says that McDowell's claim is that the subject's reasons are different in the veridical and the hallucinatory cases. While the veridical experience of seeing a hand provides a factive reason for the belief that there is a hand, the supporting reason for the belief in the hallucinatory case would be "of a different form" such as that it seems to one as if there is a hand. ${ }^{19}$ Based on two forms of rationality, it might be suggested that the given captures the type-1 rationality while hallucinatory experience has the type2 rationality. In this way, there is no contradiction in saying that hallucinatory experience plays a rational role (type-2) and the given of an experience consists in affording opportunities for knowledge (type-1).

\footnotetext{
${ }^{18}$ John McDowell, ibid., p. 470.

${ }^{19}$ Duncan Prichard, “McDowellian Neo-Mooreanism”, p. 291.
} 
Consider the kind of metaphysical disjunctivism mentioned earlier according to which different objects are presented respectively in veridical and hallucinatory experiences. It was suggested that this version of metaphysical disjunctivism might lead to the conclusion that the rational contribution of a veridical experience and its hallucinatory counterfeit are different in the sense that they both provide factive reasons for beliefs about quite different states of affairs. In this version of disjunctivism, there is no need for talking about two forms of rationality: both a verdical experience and its hallucinatory counterfeit has a given in the fully McDowellian sense.

In contrast, Prichard, following McDowell, apparently tries to preserve the rationality of ordinary perceptual judgment based on hallucinatory experiences. Yet, the rationality here can't be a matter of subjectivity. If that were the case, the veridical experience in which it also seems to one that there is a hand would also have the same form of rationality and thus the factive reason that is supposed to be provided by the veridical experience could not be a matter of subjectivity. It is no wonder then that epistemological disjunctivism has been criticized as being highly externalistic. The only plausible explanation of how those two subjectively identical experiences can differ in their rational contribution seems to be an explanation that appeals to something like reliability.

It has been pointed out that the disjunctivist's idea isn't just that two experiences can give their subject different reasons even though things look exactly the same to her in both cases. Mere difference is compatible with the existence of some common element and thus the good case may be constructed from the bad case by adding an extra element to the common element. Epistemological disjunctivists may reject the possibility of constructing the good case in this way: the good case and the bad case are radically different in their rational contribution. This reading, however, does not make the problem go away.

McDowell has claimed that the obtaining of environmental facts is not external to the subjectivity and how things are in the world can be recovered from individual experiences. Yet, if we understand subjectivity in this way, we can't make sense of the rationality of ordinary perceptual judgment based on illusory or hallucinatory experiences. Why should we think of someone who is hallucinating a hand that it would be rational for him to believe that there is a hand? We don't think that the person is merely confused or mistaken because we recognize the subjective dimension of experience in the sense that his experience is subjectively 
identical to the experience of someone who is perceiving a hand. The notion of subjectivity here can't be such that the obtaining of the fact that there is a hand can be recovered in the subjective dimension of an experience.

What lesson can we derive from the above discussion? The discussion of epistemological disjunctivism, I think, helps us to see clearly a dilemma confronting attempts to make sense of empirical rationality. If we try to be faithful to SC, this leads to a violation of McDowell's demand for receptive knowledge to render empirical rationality intelligible; and, if we take McDowells' demand seriously, we are forced to deny SC. Ironically, the Cartesain view seems to be the only way to escape this dilemma: subjectively identical experiences make the same rational contribution, viz., affording knowledge of a subjective reality. ${ }^{20}$

Experiences contribute to the goal of arriving at the true conception of the world. McDowell thinks, however, that those who accept SC can't respect this idea. This is probably what led him to attribute a heavy epistemological burden on idea of direct acquaintance with objects in the external environment, and thus invite a collision with SC. Now, is it possible to respect the contribution of experience for arriving at the true conception of the world without sacrificing the subjective constraint on empirical rationality? This is where we should turn our attention to PG.

5. To move ahead, it is helpful to go back to where McDowell started, viz., the coherentist's rejection of perceptual justification. McDowell thinks that experiences can play a rational role, not just a causal role, in our thinking about the world and thus parts company with Davidson who "recoils from the Myth of the Given all the way to denying experience any justificatory role. ${ }^{21}$ McDowell finds the coherentist's denial of the justificatory role of experience quite disturbing: the denial leads us to the picture of "frictionless spinning in void" the worry about which motivated the Myth in the first place. But at the same time, McDowell is much exercised by the coherentist's claim that only beliefs can justify a belief. The space of reasons does not extend further than the space of concepts. If experiences are taken to provide "something extra-conceptual, bare presences" as in the Myth, then experiences can't play any justificatory role. This is why McDowell thinks experiences must possess conceptual content.

${ }^{20}$ Gupta says, "the Cartesian conceptions are equivalent to the propositional given." Anil Gupta, ibid, p. 36.

${ }^{21}$ John McDowell, Mind and World, p. 14. 
An entirely different way of responding to the coherentist' denial of the justificatory role of experience is possible. Instead of asking how an experience, something so foreign to beliefs, can justify a belief, we can ask whether the rational role of an experience itself lies in justifying a belief. If an experience, whatever its nature might be, does provide rational control from outside, what is the form of the rational control? In particular, is it propositional? What is the rational role of experience, if not providing propositional foundations? By trying to answer these questions, a foundationalist may be able to accommodate the coherentist's observation that justification of any belief depends on what other beliefs one holds.

Consider our epistemic practice involving perceptual justification. Why do we take most of ordinary perceptual judgments to be justified? When I judge that there is a yellow cup in front of me, I take myself to be empirically justified because I take it for granted that the lighting is normal around me, there is no evil demon bent on deceiving me, I am not a brain-in-a-vat, and so on. My experience of seeing a yellow cup can justify "there is a yellow cup" only when I am justified to believe that there is a material world (if I take the sense-datum theory to be justified, then my experience would not give me the entitlement to believe "there is a yellow cup"). In short, if an experience justifies a belief, it does so only in conjunction with a justified background conception. ${ }^{22}$ I take this to be the fundamental insight that underlies the coherentist's denial: if an experience can justify a belief only in conjunction with a background conception, then an experience by itself does not provide a reason for holding a belief. ${ }^{23}$

The coherentist's insight is bound to be lost for any attempt to save perceptual justification within the framework of PG. Suppose that my experience has a propositional given, say, that there is a yellow cup. That is, my experience alone can give justification, defeasible or indefeasible, for the belief in that proposition. If so, there is no need for a justified background conception. This goes against the coherentist's insight. On the other hand, if my experience can justify a belief only

${ }^{22}$ In fact, something like this has been acknowledged both in scientific and ordinary practice. Against the Baconian view in which observation is taken to provide theory-neutral data for scientific theorizing, Hanson, Kuhn and others have emphasized that observation itself is theory-laden: the content and significance of our observations depends on our background theory.

${ }^{23}$ There are foundationalist epistemologies, for instance, dogmatism and phenomenal conservatism, that rejects what I call the coherentist insight. To discuss these views, however, goes beyond the scope of this paper. 
in conjunction with the justified background conception, then it is not the case that my experience alone can provide justification for the belief that there is a yellow cup. This means, within the framework of PG, the denial of the given because if there is no propositional given, then there is no given. The coherentist too is under the grip of PG in denying the justificatory role of experience.

Once we free ourselves from PG, however, there is no reason to think that the coherentist's insight can't be saved without the coherentist's denial of perceptual justification. While coherentists are right to claim that experience does not provide categorical entitlement to any belief, that is, they are right to reject the idea of propositional foundations, this does not mean that experience itself can't exert any rational influence on thinking. If an experience in conjunction with a justified background conception justifies a belief, we can conceive of the rational contribution of the experience itself as what can be obtained by subtracting the contribution of the background conception. The expression, "subtracting", need not be taken to suggest that an experience and a background conception independently supports a belief. Rather, they may jointly support a belief. More precisely, the rational contribution of an experience can be conceived as providing conditional entitlement to beliefs: given a background conception, an experience tells me what particular judgment I am entitled to make.

Conditional entitlement, to avoid possible misunderstandings, should be distinguished from categorical entitlement to beliefs in conditional propositions. To say that an experience justifies the belief that $\mathrm{P}$ only in conjunction with a justified background conception is not to say that an experience justifies the belief that if the background conception is true, then $\mathrm{P}$.

Another point that should be noted here is that in rejecting PG and opting for conditional entitlement, we are not endorsing the claim that the rational contribution of an experience is tied to a particular conception of the world. The given of an experience is supposed to capture the rational contribution of the experience alone, independently of any background conception. This, however, needs not force the thought that the given of an experience must consist in providing "something extra-conceptual, bare presences" that is somehow obtained by peeling off the contribution of the background conception. Rather, the idea of conditional entitlement is that an experience must work together with a worldview to yield justification of any belief. Given a world- view, w1, my experience entitles me to a perceptual judgment. Given a different world- view, w2, the same experience may entitle me to a different judgment. 
I have taken the idea of conditional entitlement as providing a clue to how we can save the coherentist's insight without the coherentist's denial of the rational contribution of experience. Experiences do have rational power, but, their power lies not in affording propositional foundations, but in guiding any conception of the world to a particular judgment. A worry that can be raised at this point is this. If the rationality of ordinary perceptual judgments depends on having a justified background conception of the world, where does the justification of the background conception itself come from? From the empiricist's point of view, this in turn should derive ultimately from particular judgments sanctioned by experience. The following thesis captures the dependence in both directions:

Interdependence: One's experience can justify a perceptual claim about the world if and only if the background conception that one brings in, or some relevant portion of it, is itself justified.

In accepting Interdependence, however, we seem to land in justificatory circularity and thereby come closer to the coherentist's denial of the justificatory role of experience. Isn't this precisely, as McDowell warns, where we succumb to the temptation to bring in "something extra-conceptual, bare presences" to terminate the justificatory chain, a recoil back to the Myth of the Given? Justification of a belief depends on a justified background conception which in turn depends on justified perceptual beliefs. If we can obtain one independently, we can make sense of the other. For instance, if we have a stock of perceptual beliefs that are immediately justified independently of any world-view, then we can go about adjusting our world-view in light of them. This, however, is unavailable to us once we have rejected the idea of propositional given and accepted conditional entitlement. Likewise, if we can secure the justification of a world-view from some source other than experiences, then we can make sense of perceptually justified beliefs sanctioned by the view. Yet, this would go against the idea of experiences as the ultimate source of epistemic authority. So, how do we obtain unconditional or categorical entitlement of either a background conception or a judgment?

While the problem is serious for the present line of thinking, I don't think that it is intractable. What seems to me a promising proposal is Anil Gupta's account of the given which characterizes the given in an experience in terms of a function from world-views to particular judgments. In his account, experience provides at most conditional or hypothetical entitlement to a belief, and thus, the problem of circularity arises for it too. By applying the logical tool that he developed to make 
sense of circular definitions, however, Gupta shows how, despite the circularity, we can make sense of categorical entitlement to both the background conception and the perceptual judgment. The basic idea goes like this. Suppose that we start with an arbitrary world-view and consider the rational impact of an experience given the view. What is given in an experience, e1, together with a background view of the world, yields particular judgments which are then incorporated into the background view, presenting an opportunity for a revised world-view. ${ }^{24}$ This revised world-view can again undergo revision when the subject suffers another experience, e2. In this way, a sequence of world-views can be obtained from a series of experience, $<\mathrm{e} 1, \mathrm{e} 2, \mathrm{e} 3, \ldots>$. If we start with a different world-view, a different sequence of world-views may result from the same series of experiences. Now, it may happen that there is a point after which world-views in all sequences generated by the series of experiences are identical. Call this the "convergence" of revision sequences of world-views generated by $<\mathrm{e} 1, \mathrm{e} 2, \mathrm{e} 3, \ldots>$. If a judgment belongs to a revised world-view after the convergence point, it will continue to occur in every sequence. You are entitled to a judgment in the absolute sense then if the judgment belongs to a convergent world-view that you end up with after a series of experiences, no matter which world-view you start with.

The above gives only a bare sketch of Gupta's answer to how we can make sense of categorical entitlement of judgment even though experience provides at best conditional entitlement. The details of Gupta's account, however, would require an extensive discussion. ${ }^{25}$ What is relevant for our purpose is this: Gupta's

${ }^{24}$ Anil Gupta, ibid., especially chap. 4

${ }^{25}$ In Gupta's account, the sense-datum conception is disqualified as an admissible starting point for revision process because of its peculiar behavior in possible revision processes its inability to be transformed to a different view by any series of experience. If our intent in refusing to grant the privileged status to any particular world-view and thus starting a revision process with an arbitrary world-view is to let experiences speak as fully as possible, we can't let the spoiler which is utterly insensitive to experiences to dictate the game. Gupta calls such spoiler "rigid". Yet, there may be cases of conceptions which are not rigid but still present problems for the revision process. What is needed is a plausible characterization of admissible starting point. For this issue and others, see, for instance, Ram Neta, "Empiricism about Experience", Selim Berker, "Gupta's gambit", Karl Schafer, "The rationalism in Anil Gupta's Empiricism and Experience", Christopher Frey, "On the Rational Contribution of Experiential Transparency", and Gupta's replies in "Frey on Experiential Transparency and Its Rational Role" and "Replies to Selim Berker and Karl Schafer." 
account of the given shows that once we reject PG, we may be able to respect the epistemic relevance of experience without sacrificing SC. The given of an experience, its total rational contribution, is determined by its subjective character in accordance with SC and at the same time, experiences may gradually guide us to the true conception of the world. Of course, revision processes afforded by a series of experiences, even when they yield a convergent world-view, do not guarantee that what we arrive at is the true conception of the world.

This is as it should be given the commitment to minimal realism that refuses to equate truth even with the ideal rationality. Yet, experiences are not responsible for the error or falsity that may result from having them. Consider those who endorse a now defunct theory of some phenomenon such as the caloric conception of heat. ${ }^{26}$ Friends of the caloric conception may claim that they can feel and occasionally see the caloric fluid, and make judgments about the heat of a substance by saying, for instance, "the water in the kettle is at high caloric pressure". According to Gupta's account, the given of their experience of the heat is not responsible for the falsity of the ensuing judgment. The given did yield the false judgment, but only in conjunction with the caloric conception of heat. The same given may yield a different judgment when a different conception is brought in. The falsity of the judgment made by friends of caloric is due to the conception that they bring in to make sense of the experienced world.

6. I will finish the paper by considering an objection to the idea of the given as conditional entitlement. By rejecting PG, we are saying that an experience by itself does not justify a proposition. McDowell says that this negative thesis is dubious because the very notion of "experience by itself" that figures in it, the notion of "experience independent of view", is mistaken. ${ }^{27}$ McDowell has questioned the very separation of view and experience on the Kantian ground that a view is woven into the fabric of experience - "experiences themselves are states or occurrences that inextricably combine receptivity and spontaneity." 28

\footnotetext{
${ }^{26}$ This example is due to Paul Churchland, Scientific Realism and the Plasticity of Mind, p. 19.

${ }^{27}$ In his comments on Gupta, McDowell suggests that to talk about an aspect of experience that is independent of views is essentially tantamount to the Cartesian view. But as I have argued, to take the subjective character of an experience seriously in characterizing its epistemological significance is not to endorse the idea of subjective foundations. John McDowell, "The Given in Experience: Comment on Gupta", p.473.

${ }^{28}$ John McDowell, Mind and World, p. 24.
} 
Now, how does this inseparability of experience and view bear on the epistemological concern? If McDowell is correct, some of us would be wrong to think that although world-view and cues, or theory and data, are interdependent, they are as distinct as things get. But this may be irrelevant for the epistemological concern in question. Although views may causally or metaphysically shape experience, this does not necessarily undermine the epistemological independence of experience. Even if a view is woven into the fabric of experience, experiences may have some other aspect that is epistemologically significant. ${ }^{29}$ In fact, there must be such an aspect if we want to preserve the epistemological autonomy of experience.

The Kantian conception, if it is taken to be relevant for the epistemological concern, would undermine the epistemological independence of experience from views. Given the epistemological reading of the Kantian conception, it simply makes no sense to talk about what perceptual judgments an experience issues with respect to a different view. Indeed, McDowell goes on to make a strong claim: "in a sense everything in her experience confirms the background." ${ }^{30}$ This means that experience can never overturn the background, which is unacceptable from the perspective of an empiricism that attributes to experiences the ultimate epistemic authority. The idea of genuine rational control from outside on our thinking would be lost.

Of course, the worry about the Kantian conception would be misplaced if the view that is interwoven into our experiences is the correct one. If the background view is correct, then an experience equipped with the conceptual content that things are thus and so, as McDowell claims, may amount to, in some veridical cases, a direct pick-up of the fact that things are thus and so and thus enable the layout of the reality itself to exert rational influence. But how do we know that our world-view that we bring in to make sense of the empirical world is the correct one?

...it is only against the background knowledge that an experience is what it is, affording or seeming to afford opportunity for knowing at all. If we want "experience" to mean something epistemically significant, we must recognize that the ability to have experiences at all is something we acquire as we acquire the background knowledge. ${ }^{31}$

\footnotetext{
${ }^{29}$ Anil Gupta, ibid., p. 106.

${ }^{30}$ John McDowell, “The Given in Experience: Comment on Gupta”, p. 473.

${ }^{31}$ John McDoWell, Ibid., p. 473.
} 
McDowell says here that experiences are possible only when one has the background knowledge. As McDowell acknowledges, the background knowledge can't be straightforwardly empirical because it must be already in place for empirical learning to be possible. Again, where does the background knowledge itself come from? Furthermore, if the background knowledge is needed for an experience to afford or seem to afford opportunity for knowledge, it follows that the background knowledge is needed for an experience to merely seem to afford knowledge. This is surprising. Why is it that the background knowledge is needed for an experience's merely seeming to afford knowledge? Even if a subject's conception of the world and his place in it is too confused to be counted as a case of knowledge, his experiences may nonetheless make it seem to him that he sees that things are thus and so. ${ }^{32}$ Those people whose judgments are shaped by the caloric conception of heat may claim that they can simply see or feel "the pressure of the contained caloric."

It seems to me that McDowell denies the epistemological autonomy of experience because he thinks that to talk about epistemological significance that an experience has independently of any conception of the world already commits us to the Myth of the Given which requires us to somehow step outside of all conceptual schemes and grasp the pure given uncontaminated by any of them. Thus, it is concluded that epistemological significance of an experience must be tied to a particular conception and that experiences must have conceptual content in order to be rationally linked to thinking. Anything short of believing in this strikes McDowell as a case of falling back into the Myth of the Given.

But it is not obvious at all that the epistemological autonomy of experience forces the predicament that the Myth of the Given puts us into. What motivates us to seek for the rational constraint from outside in the first place? Is it because we think we can stand outside of all conceptual schemes and grasp the pure given uncontaminated by any of them? No, such stance is simply unavailable to us. Rather, what motivates the epistemological autonomy of experience is the realization that we come into the world with no privileged conception of the world. Surely, as McDowell correctly emphasizes, the Myth of the Given, the appeal to "something extra-conceptual, bare presences", is simply useless because it provides at best exculpation instead of justification. Yet, as I have argued, no such appeal is needed at all for us to take experiences as being capable of playing

32 Anil Gupta, "Equivalence, Reliability, and Convergence: Replies to McDowell, Neta, and Peacocke", p. 495. 
the role of adjudicating our conception of the world. The possibility that the epistemological autonomy of experience can be sustained without falling back to the Myth of the given can be readily recognized once we move to an alternative account of the epistemological role of experience, an account built on the idea of conditional entitlement, which promises to accommodate independently plausible theses such as SC, the epistemic relevance and the coherentist's insight.

In contrast, the notion of direct presentation of a fact is brought back and given a heavy epistemological work to do in McDowell's disjunctivism. Isn't this precisely a case of falling back into the Myth? We are told that it isn't because direct presentation is somehow inextricably combined with conceptual activities. This way of avoiding the Myth, even if it can be worked out, simply gives up the epistemological autonomy of experience and fails to do justice to the initial reason that we had for seeking the rational constraint from outside, viz., that we come into the world with no privileged conception of the world. The difficulties here, I suspect, are symptomatic of the tenacious grip that the framework of PG has on our thinking. They are not inevitable at all once we free ourselves from the propositional framework.

Undoubtedly, McDowell is much concerned with the problem of gaining perceptual access to the objective world, which he takes to be unduly aggravated by the subjective constraint on empirical rationality. That there is an objective reality is surely a part of our ordinary conception of the world. Yet, how is the ordinary conception itself justified? The subjectivist orientation embodied in SC need not be thought as getting in the way of accessing the objective world. Quite the contrary, experiences, when their logical character is properly understood, can provide a vindication of the very conception that there is an objective, independent world.

Being inextricably combined with conceptual activities, direct presentation, in McDowell's account, serves the role of bringing the independent reality within the conceptual sphere. It is no wonder then that his account invites the kind of protest that he himself acknowledges, viz., the protest that the disjunctivist's attempt to locate perceptible facts inside the conceptual sphere is a sort of idealism and a case of slighting the independence of reality. ${ }^{33}$ McDowell may well be right to point out that such protest is motivated by insufficient appreciation of the uselessness of the Given. It seems to me misleading, however, to say that McDowell's own view has an entirely different motivation.

Bosuk YOON, Ewha Womans University, South Korea 


\section{REFERENCES}

Berker, Selim. 2011. “Gupta’s gambit”, Philosophical Studies, 152:17-39.

Brewer, Bill. 1999. Perception and Reason, Oxford University Press.

Byrne, Alex and Logue, Heather. 2008. "Either/Or", in Adrian Haddock and Fiona Mcpherson (eds), Disjunctivism: Perception, Action, Knowledge, Oxford University Press.

Cohen, Stewart. 2002. "Basic Knowledge and the Problem of Easy Knowledge", Philosophy and Phenomenological Research, Vol.65, Number 2.

Crane, Tim. 2006. “Is There a Perceptual Relation?”, in Tamar Gendler and John Hawthorne (eds), Perceptual Experience, Oxford University Press.

Frey, Christopher. 2011. "On the Rational Contribution of Experiential Transparency", Philosophy and Phenomenological Research, Vol. LXXX II No.3.

Gaskin, Richard, 2008, "Review of Empiricism and Experience", Mind, Vol.117. Gupta, Anil. 2006. Empiricism and Experience, Oxford University Press.

Gupta, Anil. 2009. "Equivalence, Reliability, and Convergence: Replies to McDowell, Peacocke, and Neta", Philosophy and Phenomenological Research, Vol. LXXIX No.2.

Gupta, Anil. 2011. "Replies to Selim Berker and Karl Schafer", Philosophical Studies, 152:41-53.

Gupta, Anil. 2011. "Frey on Experiential Transparency and Its Rational Role", Philosophy and Phenomenological Research, Vol. LXXX II No.3.

Heck, Richard. 2000. "Nonconceptual Content and the "Space of reasonss"”, The Philosophical Review, Vol. 109, No.4.

Huemer, Michael. 2006. "Phenomenal Conservatism and the Internalist Intuition", American Philosophical Quarterly. Vol 43, Number 2.

Markie, Peter. 2005. "The Mystery of Direct Perceptual Justification", Philosophical Studies 126. 
Martin, M. G. F.. 2006. "On Being Alienated”, in Tamar Gendler and John Hawthorne (eds), Perceptual Experience, Oxford University Press.

McDowell, John. 1982. "Criteia, Defeasibility, and Knowledge", Proceedings of the British Academy, 68: 455-79. Reprinted in Meaning, Knowledge, and Reality, Harvard University Press.

McDowell, John. 1986. "Singular Thought and the Extent of Inner Space", in Philip Pettit and John McDowell (eds), Subject, Thought, and Context, Clarendon Press, Oxford. Reprinted in Meaning, Knowledge, and Reality, Harvard University Press.

McDowell, John. 1994. Mind and World, Cambridge, MA: Harvard University Press.

McDowell, John. 2008. "The Disjunctive Conception of Experience as Material for a Transcendental Argument", in Adrian Haddock and Fiona Mcpherson (eds), Disjunctivism: Perception, Action, Knowledge, Oxford University Press.

McDowell, John, 2008, "Avoiding the Myth of the Given", in John McDowell: experience, norm, and nature, Jacob Lindgaard (ed), Blackwell Publishing Company.

McDowell, John. 2009. "The Given in Experience: Comment on Gupta", Philosophy and Phenomenological Research, Vol. LXXIX No.2.

Neta, Ram. 2008. "In Defence of Disjunctivism", in Adrian Haddock and Fiona Mcpherson (eds), Disjunctivism: Perception, Action, Knowledge, Oxford University Press.

Neta, Ram. 2009. "Empiricism about Experience", Philosophy and Phenomenological Research, Vol.LXXIX No.2.

Prichard, Duncan. 2008. "McDowellian Neo-Mooreanism", in Adrian Haddock and Fiona Mcpherson (eds), Disjunctivism: Perception, Action, Knowledge, Oxford University Press.

Prichard, Duncan, 2012, Epistemological Disjunctivism, Oxford University Press.

Pryor, Jim. 2000. “The Skeptic and the Dogmatist”, Nous 34:4. 
Pryor, Jim. 2004. "What's wrong with Moore's argument?", Philosophical Issues, 14, Epistemology.

Schafer, Karl. 2011. "The rationalism in Anil Gupta's Empiricism and Experience", Philosophical Studies, 152: 1-15.

Stroud, Barry. 2009. "Scepticism and the Senses", European Journal of Philosophy 17:4, pp.559-570.

White, Roger. 2006. "Problems for Dogmatism”, Philosophical Studies 131.

Wright, Crispin. 2002. "Anti-Sceptics Simple and Subtle: G.E. Moore and John McDowell”, Philosophy and Phenomenological Research, Vol 65, Number 2.

Wright, Crispin. 2008. “Comments on John McDowell's “The Disjunctive Conception of Experience as Material for a Transcendental Argument"', in Adrian Haddock and Fiona Mcpherson (eds), Disjunctivism: Perception, Action, Knowledge, Oxford University Press. 